\title{
World Journal of Early prediction of acute kidney injury in neonates with cardiac surgery
}

Shanshan Shi, ${ }^{1}$ Jiajie Fan, ${ }^{1}$ Qiang $S h u^{2}$

To cite: Shi S, Fan J, Shu Q. Early prediction of acute kidney injury in neonates with cardiac surgery. World Jnl Ped Surgery 2020;3:e000107. doi:10.1136/ wjps-2019-000107

Received 29 December 2019 Revised 12 May 2020

Accepted 14 May 2020
Check for updates

\section{(C) Author(s) (or their} employer(s)) 2020. Re-use permitted under CC BY-NC. No commercial re-use. See rights and permissions. Published by BMJ.

${ }^{1}$ Cardiac Intensive Care Unit, The Children's Hospital of Zhejiang University School of Medicine, Hangzhou, China

${ }^{2}$ Department of Thoracic and Cardiovascular Surgery, The Children's Hospital of Zhejiang University School of Medicine, Hangzhou, China

Correspondence to Dr Qiang Shu; shuqiang@zju. edu.cn

\section{ABSTRACT}

Background Acute kidney injury (AKI) occurs in $42 \%-64 \%$ of the neonatal patients experiencing cardiac surgery, contributing to postoperative morbidity and mortality. Current diagnostic criteria, which are mainly based on serum creatinine and hourly urine output, are not sufficiently sensitive and precise to diagnose neonatal AKI promptly. The purpose of this review is to screen the recent literature, to summarize the novel and cost-effective biomarkers and approaches for neonatal AKI after cardiac surgery (CS-AKI), and to provide a possible research direction for future work.

Data sources We searched PubMed for articles published before November 2019 with pertinent terms. Sixty-seven articles were found and screened. After excluding 48 records, 19 articles were enrolled for final analysis. Results Nineteen articles were enrolled, and 18 possible urinary biomarkers were identified and evaluated for their ability to diagnose CS-AKI. Urinary neutrophil gelatinase-associated lipocalin (UNGAL), serum cystatin C (sCys), urinary human kidney injury molecule-1 (uKIM1), urinary liver fatty acid-binding protein (UL-FABP) and interleukin-18 (ulL-18) were the most frequently described as the early predictors of neonatal CS-AKI.

Conclusions Neonates are vulnerable to CS-AKI. UNGAL, sCys, uL-FABP, uKIM-1 and ulL-18 are potential biomarkers for early prediction of neonatal CS-AKI. Renal regional oxygen saturation by near-infrared spectroscopy is a noninvasive approach for early identification of neonatal AKI. Further work should focus on exploring a sensitive and specific combined diagnostic model that includes novel biomarkers and other complementary methods.

\section{INTRODUCTION}

Acute kidney injury (AKI), also known as acute kidney failure, covers a wide spectrum of clinical states, from subtle increase of serum creatinine ( $\mathrm{sCr}$ ) to serious injury that requires renal replacement. ${ }^{12}$ AKI is a common complication of patients after cardiac surgery both in adults and in children, and is recognized as one of the most important factors contributing to postoperative morbidity and mortality. ${ }^{3-5}$

The mechanism of acute kidney injury after cardiac surgery (CS-AKI) is not well understood and can involve multiple factors. Hemodynamic fluctuation, inflammatory/immune factors, coagulation and neurohumoral regulation disorder might play essential roles in the development of CS-AKI. Neonates are vulnerable to CS-AKI. Neonatal renal physiological features and several comorbidities and associated conditions have proved to be highrisk factors for neonatal CS-AKI (box 1). The reported incidence of AKI following pediatric cardiac surgery was $30 \%-50 \%$, whereas in the neonatal population the incidence was $42 \%-64 \%$, depending on the definition of AKI and the enrolled cardiac lesions (table 1). The occurrence of CS-AKI has been proven to be associated with short-term and long-term outcomes in neonates. Neonates with CS-AKI require longer duration in mechanical ventilation, intensive care unit stay and hospitalization. The mortality rate of neonates receiving dialysis after cardiac surgeries is 6.4 times higher than that of neonates without AKI. Furthermore, a 2-year follow-up study indicates that the infants surviving from Acute Kidney Injury Network stage 2 and 3 in their neonatal period have lower $\mathrm{Z}$ score for height. ${ }^{46}$ Establishing an 'alarm system' to identify patients at high risk for AKI might facilitate the initiation of prompt intervention and might improve the outcomes. The purpose of this review is to summarize the recent literature and to describe the novel and cost-effective biomarkers and tools for early diagnosis of neonatal CS-AKI.

\section{DIAGNOSIS OF CS-AKI IN NEONATAL PATIENTS}

Several definitions for AKI have been launched since 2004, including the Risk, Injury, Failure, Loss, and End-Stage Kidney Disease (RIFLE), Acute Kidney Injury Network (AKIN), and the Kidney Disease: Improving Global Outcomes (KDIGO) classifications. ${ }^{7-10}$ The disparities and similarities among these definitions are listed in table 2. In the case of patients with cardiac procedures, severe AKI stages are related to adverse outcome and higher mortality; however, the debate on the standard criteria for CS-AKI remains unsettled and depends on the patient population enrolled and the validated version of each criterion (such as adding a diagnostic 


\section{Box 1 The mechanisms of neonatal CS-AKI}

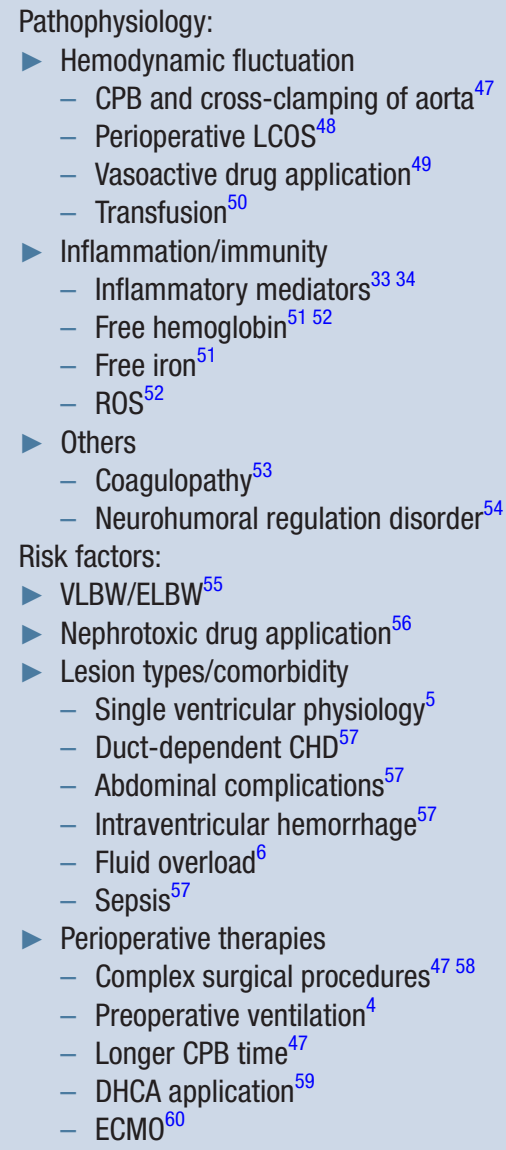

CHD, congenital heart disease; CPB, cardiopulmonary bypass; CS-AKI, acute kidney injury after cardiac surgery; DHCA, deep hypothermia cardiac arrest; ECMO, extracorporeal membrane oxygenation; ELBW, extremely low birth weight (birth weight $<1000 \mathrm{~g}$ ); LCOS, low cardiac output syndrome; ROS, reactive oxygen species; VLBW, very low birth weight (birth weight $<1500 \mathrm{~g}$ ).

period to AKIN and KDIGO systems). ${ }^{11} 12$ Generally, RIFLE is much more sensitive in identifying the risk-stage patients, and the AKIN and KDIGO may be more specific in diagnosing AKI, particularly in recognizing stage 3 patients. Nevertheless, all three classifications are based on the change of sCr directly and indirectly. The main challenges of diagnosing neonatal AKI are focused on the following items:
- The promptness of sCr: sCr obviously will not change until $25 \%-50 \%$ of renal function is lost, and the effect of fluid dilution may conceal the real change in sCr. Therefore, the rise in $\mathrm{sCr}$ in neonatal patients always delays until 36-48 hours after surgery. Patients in an early phase of AKI might not be discerned and would miss timely intervention.

- Some neonates present non-oliguric AKI, especially preterm neonates due to higher proportion of body water. ${ }^{13}$ Thus, urine output (UO) less than $0.5 \mathrm{~mL} /$ $\mathrm{kg} / \mathrm{hour}$ is not sufficient, and some researchers refuse to take UO as a reliable indicator of CS-AKI.

- The number of nephrons and the tubular maturity are closely related to gestational age. ${ }^{11} 1214$ The renal blood flow improves gradually within the initial several weeks after birth. However, glomerular filtration rate (GFR) will not be steady until 2 years of age.${ }^{15}$ Accordingly, gestational age, birth weight and postnatal age all have a potential impact on the susceptibility of neonates to AKI.

\section{EARLY PREDICTION OF CS-AKI IN NEONATAL PATIENTS}

Regarding the limitations of sCr and UO in early recognition of CS-AKI in neonatal patients, tremendous research has been performed to explore possible serum and urine biomarkers and other non-invasive methods for discriminating patients at high risk for AKI.

\section{Serum and urine biomarkers predicting neonatal CS-AKI}

We searched PubMed with terms 'neonate, cardiac surgery, acute kidney injury', 'neonate, cardiac surgical procedure, acute kidney injury' and 'neonate, cardiopulmonary bypass, acute kidney injury' separately. Clinical trial, clinical study, controlled clinical trial, multicenter study, observational study and randomized controlled trial published before November 2019 were considered. A total of 67 articles were screened. After excluding 48 of these records, 19 articles were analyzed. The methodology is explicated in figure 1.

It is notable that, in the case of neonates, the application of urinary biomarkers for early prediction or for adding diagnostic value to $\mathrm{sCr}$ is prevalent. Urine samples were applied in a total of 15 of the 19 studies

Table 1 Incidence of CS-AKI in neonates

\begin{tabular}{|c|c|c|c|c|c|}
\hline Study & Population & Cases & Cardiac lesion & AKI definition & Incidence (\%) \\
\hline Alabbas et $a l^{60}$ & $<28$ days & 122 & & AKIN & 62 \\
\hline Morgan et al ${ }^{4}$ & $\leq 6$ weeks & 264 & & AKIN & 64 \\
\hline Piggott et a ${ }^{6}$ & 6-29 days & 95 & & AKIN & 45 \\
\hline Park et al ${ }^{50}$ & $<30$ days & 60 & & KDIGO & 48 \\
\hline Carlo et $a l^{61}$ & $<30$ days & 56 & & KDIGO & 75 \\
\hline SooHoo et $a^{62}$ & $<30$ days & 95 & HLHS & KDIGO & 42 \\
\hline
\end{tabular}

AKI, acute kidney injury; AKIN, Acute Kidney Injury Network; CS-AKI, acute kidney injury after cardiac surgery; HLHS, hypoplastic left heart syndrome; KDIGO, Kidney Disease: Improving Global Outcomes. 


\begin{tabular}{|c|c|c|c|c|c|c|c|c|}
\hline \multicolumn{3}{|l|}{ AKIN } & \multicolumn{3}{|l|}{ RIFLE } & \multicolumn{3}{|c|}{ KDIGO } \\
\hline Stage & $\mathrm{sCr}$ & UO & Stage & eGFR & UO & Stage & $\mathrm{sCr}$ & UO \\
\hline 1 & $\begin{array}{l}\text { Rise of } \geq 0.3 \mathrm{mg} / \mathrm{dL} \\
\text { or } 1.5-1.9 \text { times } \\
\text { the baseline. }\end{array}$ & $\begin{array}{l}<0.5 \mathrm{~mL} / \mathrm{kg} / \\
\text { hour for } 6 \\
\text { hours. }\end{array}$ & Risk & $\begin{array}{l}25 \% \\
\text { decrease } \\
\text { in eGFR. }\end{array}$ & $\begin{array}{l}<1.5 \mathrm{~mL} / \mathrm{kg} / \\
\text { hour for } 24 \\
\text { hours. }\end{array}$ & 0 & $\begin{array}{l}\text { No change or } \\
\text { rise of }<0.3 \mathrm{mg} / \\
\mathrm{dL} \text {. }\end{array}$ & $\begin{array}{l}\geq 0.5 \mathrm{~mL} / \mathrm{kg} / \\
\text { hour. }\end{array}$ \\
\hline 2 & $\begin{array}{l}2-3 \text { times the } \\
\text { baseline. }\end{array}$ & $\begin{array}{l}<0.5 \mathrm{~mL} / \mathrm{kg} / \\
\text { hour for }>12 \\
\text { hours. }\end{array}$ & Injury & $\begin{array}{l}50 \% \\
\text { decrease } \\
\text { in eGFR. }\end{array}$ & $\begin{array}{l}<1.0 \mathrm{~mL} / \mathrm{kg} / \\
\text { hour for } 24 \\
\text { hours. }\end{array}$ & 1 & $\begin{array}{l}\text { Rise of } \geq 0.3 \mathrm{mg} / \\
\mathrm{dL} \text { or } 1.5-1.9 \\
\text { times the } \\
\text { baseline. }\end{array}$ & $\begin{array}{l}<0.5 \mathrm{~mL} / \mathrm{kg} / \\
\text { hour for } 6-12 \\
\text { hours. }\end{array}$ \\
\hline \multirow[t]{3}{*}{3} & $\begin{array}{l}3 \text { times the } \\
\text { baseline or rise of } \\
\geq 4.0 \mathrm{mg} / \mathrm{dL} \text { with } \\
\text { acute rise of at } \\
\text { least } 0.5 \mathrm{mg} / \mathrm{dL} \text {. }\end{array}$ & $\begin{array}{l}<0.3 \mathrm{~mL} / \mathrm{kg} / \\
\text { hour for } 24 \\
\text { hours or anuria } \\
\text { for } 12 \text { hours. }\end{array}$ & Failure & $\begin{array}{l}75 \% \\
\text { decrease } \\
\text { in eGFR. }\end{array}$ & $\begin{array}{l}<0.7 \mathrm{~mL} / \\
\mathrm{kg} / \text { hour for } \\
24 \text { hours or } \\
\text { anuria for } 12 \\
\text { hours. }\end{array}$ & 2 & $\begin{array}{l}2-2.9 \text { times the } \\
\text { baseline. }\end{array}$ & $\begin{array}{l}<0.5 \mathrm{~mL} / \mathrm{kg} / \\
\text { hour for } \geq 12 \\
\text { hours. }\end{array}$ \\
\hline & & & Loss & \multicolumn{2}{|c|}{$\begin{array}{l}\text { Persistent failure of }>4 \\
\text { weeks. }\end{array}$} & 3 & $\begin{array}{l}3 \text { times the } \\
\text { baseline or rise } \\
\text { of } \geq 2.5 \mathrm{mg} / \mathrm{dL} \text { or } \\
\text { initiation of RRT. }\end{array}$ & $\begin{array}{l}<0.5 \mathrm{~mL} / \\
\mathrm{kg} / \mathrm{hour} \text { for } \\
\geq 24 \text { hours or } \\
\text { anuria for } \geq 12 \\
\text { hours. }\end{array}$ \\
\hline & & & End stage & \multicolumn{2}{|c|}{$\begin{array}{l}\text { Persistent failure of }>3 \\
\text { months. }\end{array}$} & & & \\
\hline
\end{tabular}

Baseline refers to the lowest previous level of sCr.

AKIN, Acute Kidney Injury Network; eGFR, estimated glomerular filtration rate; KDIGO, Kidney Disease: Improving Global Outcomes; RIFLE, Risk, Injury, Failure, Loss, and End-Stage Kidney Disease; RRT, renal replacement treatment; sCr, serum creatinine; UO, urine output.

we collected. The plausible explanations are that urineoriented biomarkers can reflect both the structural damage and the functional injury of the kidney directly and that urinary samples can be obtained non-invasively from Foley catheter after cardiac surgery. The utilities of novel biomarkers in neonates are illustrated in table 3 .

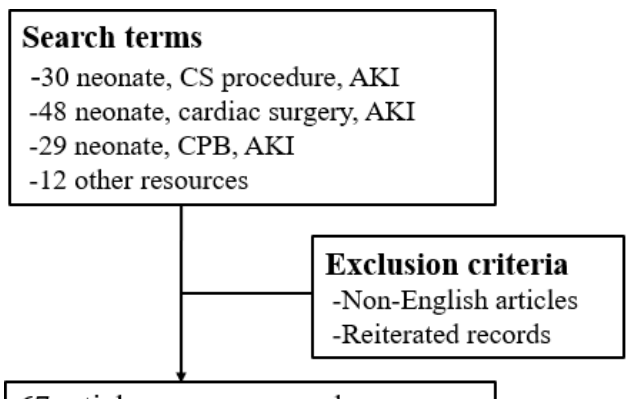

67 articles were screened.

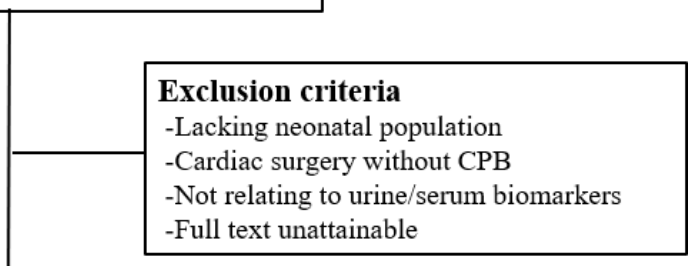

19 full text were reviewed deliberately.

Figure 1 Literature retrieval process. AKI, acute kidney injury; CPB, cardiopulmonary bypass; CS, cardiac surgical procedure.

\section{Proximal tubular cell biomarkers}

Neutrophil gelatinase-associated lipocalin (NGAL), kidney injury molecule-1 (KIM-1) and liver fatty acidbinding protein (L-FABP) are secreted by the proximal tubular epithelial cells. Increases in concentration indicate tubular injury.

Elevating serum and urinary NGAL levels have been widely identified in patients with AKI with multiple etiologies. The relationship between NGAL and CS-AKI in neonates was also evaluated recently. In four studies including neonates, the rise in urinary NGAL (uNGAL) occurs as early as about 2 hours after surgery and shows good diagnostic ability for CS-AKI regardless of AKI definitions, even normalized by creatinine, and can be one of the independent risk factors for adverse clinical outcomes. ${ }^{16-22}$ Other studies also indicate that the value of UNGAL within 12 hours after surgery is a strong predictor of CS-AKI, and it is significantly associated with poor outcomes. ${ }^{21} 2324$ A study including 30 neonatal patients concludes that, besides postoperative serum NGAL (sNGAL), preoperative sNGAL is also a potential indicator of CS-AKI. ${ }^{25}$ But the conclusions are not always on the same page. A study published in 2018 with 59 neonates and infants reveals that both uNGAL and sNGAL are not indicators of CS-AKI. But in the cases experiencing longer cardiopulmonary bypass (CPB) time ( $\geq 75 \mathrm{~min}$ ), uNGAL increases significantly as early as 2 hours after surgery. ${ }^{26}$

KIM-1, a type 1 transmembrance protein, could not be detected in urine normally, but increases promptly after 
Table 3 Literature review of novel biomarkers predicting CS-AKI in neonates

\begin{tabular}{|c|c|c|c|}
\hline Author, year & Population & $\begin{array}{l}\text { AKI } \\
\text { definition }\end{array}$ & Novel biomarkers predicting CS-AKI \\
\hline Krawczeski et al, $2011^{16}$ & $35 / 375$ & AKIN & uNGAL, sNGAL \\
\hline Cantinotti et al, $2012^{17}$ & $26 / 135$ & AKIN & uNGAL, BNP, uNGAL/urinary creatinine ratio \\
\hline Ricci et al, $2012^{18}$ & $50 / 160$ & RIFLE & UNGAL \\
\hline Peco-Antić et al, $2012^{23}$ & $20 / 112$ & $\geq 25 \%$ decrease in eCCl & sCys C, sNGAL, uNGAL, uKIM-1, uL-FABP \\
\hline Hassinger et al, $2012^{31}$ & $100^{*}$ & RIFLE & sCys C \\
\hline Zappitelli et al, $2012^{41}$ & $294^{*}$ & AKIN & Urine albumin to creatinine ratio \\
\hline Hazle et al, $2013^{24}$ & $42^{\star}$ & AKIN/KDIGO & uNGAL, ulL-18, uKIM-1, sCys C \\
\hline Seitz et al, $2013^{32}$ & $139^{*}$ & RIFLE & uNGAL, sCys C \\
\hline Zheng et al, $2013^{35}$ & $58^{\star}$ & AKIN & uMA, NAG and $\alpha 1-M G-M G$, uNGAL and ulL-18 \\
\hline Mamikonian et al, $2014^{19}$ & $40^{*}$ & RIFLE & uNGAL \\
\hline Alcaraz et al, $2014^{20}$ & $106^{*}$ & RIFLE & uNGAL, uNGAL/Cr \\
\hline Bojan et al, $2016^{21}$ & $75 / 200$ & AKIN & uNGAL, urine creatinine normalized uNGAL \\
\hline Herbert et al, $2015^{22}$ & $17^{*}$ & RIFLE & uNGAL, sCys C \\
\hline Tew et al, $2017^{40}$ & $187 / 814$ & AKIN & Nadir value of platelet \\
\hline Reiter et al, $2018^{26}$ & $59^{*}$ & RIFLE & UNGAL \\
\hline Gist et al, $2018^{27}$ & $31^{*}$ & KDIGO & uTIMP2*IGFBP-7, uKIM-1 \\
\hline Burra et al, $2018^{38}$ & $51^{*}$ & KDIGO & Serum phosphorus \\
\hline Volovelsky et al, $2018^{39}$ & $81^{*}$ & KDIGO & Serum FGF23 \\
\hline Schroeder et al, $2019^{25}$ & 30 & KDIGO & sNGAL \\
\hline
\end{tabular}

The population enrolled in the studies is presented as neonate/total cases.

*Specific number of neonates was not described in the study.

AKI, acute kidney injury; AKIN, Acute Kidney Injury Network; BNP, brain natriuretic peptide; BNP, brain natriuretic peptide ; CS-AKI, acute kidney injury after cardiac surgery; eCCl, estimated creatinine clearance; FGF23, fibroblast growth factor 23; IGFBP-7, insulin-like growth factor-binding protein type 7; KDIGO, Kidney Disease: Improving Global Outcomes; $\alpha 1$-MG, $\alpha 1$-microglobulin; RIFLE, Risk, Injury, Failure, Loss, and End-Stage Kidney Disease; sCys C, serum cystatin C; sNGAL, serum neutrophil gelatinase-associated lipocalin; ulL-18, urinary IL18; uKIM-1, urinary KIM-1; uL-FABP, urinary L-FABP; uMA, urinary microalbumin; UNGAL, urinary neutrophil gelatinase-associated lipocalin; UTIMP2, urinary tissue inhibitor metalloproteinase type 2.

proximal tubular epithelial cells injury, boosting epithelial repair and phagocytosis. In a study with patients younger than 1 year old (including neonates), urinary KIM-1 at 6 hours after CPB has predictive power for AKI, with an AUC of $0.66 .{ }^{27} \mathrm{~L}-\mathrm{FABP}$, which is involved in fatty acid metabolism, expresses highly in ischemic insult and is a sensitive predictor of kidney diseases. Urinary L-FABP (uL-FABP) increases at 2, 6 and 24 hours after surgery and proves to be a strong indicator of CS-AKI in neonatal and infants, and the AUC for UL-FABP is $0.89,0.75$ and 0.87 , respectively. ${ }^{23}$

\section{Biomarkers of GFR}

Cystatin C, a low-molecular-weight protein, is filtered freely by the glomerulus. Compared with creatinine, the serum cystatin $\mathrm{C}$ ( $\mathrm{sCys} \mathrm{C}$ ) level would not be influenced by maternal level, gestational age, sex and muscle mass. Taking these theoretical properties into consideration, Cys $\mathrm{C}$ sounds an ideal marker of renal function in neonates in different clinical situations. ${ }^{28-30}$

In the studies of neonates undergoing cardiac surgery, significant upregulation of $\mathrm{s}$ Cys $\mathrm{C}$ is found at 2 and 8 hours following $\mathrm{CPB}$ and has been proven to be an independent predictor of AKI. ${ }^{31} 32$ Likewise, elevating urinary cystatin $\mathrm{C}$ is also detected at a very early period after surgery $(0,2$ hours) in patients with poor outcomes. ${ }^{24}$

\section{Inflammatory biomarkers}

Systemic inflammatory response is a major cause of CS-AKI. Research studies have indicated that the traditional inflammatory mediators, including interleukins (ILs), interferon-gamma, tumor necrosis factor-alpha, granulocyte colony-stimulating factor, granulocytemacrophage colony-stimulating factor, $\mathrm{C}$ reactive protein and so on, do upregulate early after cardiac surgery. Theoretically, these phenomena are more likely to be a reaction to CPB than to the renal insult per se. ${ }^{3334} \mathrm{IL}-18$, a proinflammatory cytokine, is activated and released into urine after ischemic insult of proximal tubules. However, the role of urinary IL-18 (uIL-18) in predicting AKI is still controversial. Zheng et $a l^{35}$ reveal that in patients developing AKI uIL-18 has the best predictive ability at 4 hours after surgery, with an AUC of 0.835 . In contrast, Morgan $e t a l^{33}$ do not find a significant difference in IL-18 between AKI and non-AKI patients. 
Other biomarkers

In addition to the mainstream biomarkers mentioned, several other biomarkers are reported as potential predictors of CS-AKI. Tissue inhibitor metalloproteinase type 2 (TIMP-2) and insulin-like growth factor-binding protein type 7 (IGFBP-7) are two molecules provoking G1 cell cycle arrest, playing key roles in the development of and recovery from AKI. ${ }^{36}$ Meersch $e t a l^{37}$ identified that urinary TIMP-2*IGFBP-7 concentration demonstrates a highly early predictive value for AKI (4 hours after surgery) in infants and children. Likewise, a recent study including infants and neonates reports that urinary TIMP-2*IGFBP-7 concentration at 12 hours after CPB strongly indicates the occurrence of AKI, with an AUC of $0.71 .^{24}$

Electrolytic and metabolic disorders are also involved in the kidney insult after cardiac surgery, and persistent hyperphosphatemia may prognose severe renal impairments. Burra et als $\mathrm{s}^{38}$ study found that serum phosphorus level increased significantly at 24 hours postoperatively in patients with AKI and could be another alternative predictor of CS-AKI. The rise in the preoperative and postoperative levels of fibroblast growth factor 23, a hormone which regulates renal phosphate reabsorption, has also been proven to be associated with severe AKI. ${ }^{39}$

Furthermore, thrombocytopenia has been identified as a risk factor for CS-AKI, and the degree of the nadir platelet count has a strong relationship with the severity of AKI. ${ }^{40}$ First postoperative urine albumin to creatinine ratio is also an available marker predicting stage 2 and 3 AKI in patients younger than 2 years old. ${ }^{41}$ Serum gelsolin is significantly decreased at 6 hours following CPB in patients with AKI and has been proven to be an excellent predictor of CS-AKI in neonates and young infants. ${ }^{42}$

In general, NGAL, cystatin C, L-FABP, KIM-1 and IL-18 were the most frequently detected for early prediction of CS-AKI. Table 4 illustrates the common time period for each biomarker, all of which occur much earlier than the rise in sCr. However, it is unavoidable that these findings have some limitations. First, the majority of studies were conducted in single-center manners with non-uniform AKI criteria and with limited sample sizes. Second, the findings in this review are obtained from

\begin{tabular}{ll}
\hline $\begin{array}{l}\text { Table } 4 \\
\text { neonatal CS-AKI }\end{array}$ & Time \\
\hline Biomarker & $2-12$ hours postoperatively \\
\hline UNGAL & $2-8$ hours postoperatively \\
SCys C & $2-6$ hours postoperatively \\
uL-FABP & $6-12$ hours postoperatively \\
uKIM-1 & $4-12$ hours postoperatively \\
\hline ulL-18
\end{tabular}

CS-AKI, acute kidney injury after cardiac surgery; sCys C, serum cystatin C; ulL-18, urinary interleukin-18; uKIM-1, urinary kidney injury molecule-1; uL-FABP, urinary liver fatty acid-binding protein; uNGAL, urinary neutrophil gelatinase-associated lipocalin. studies including both neonatal and pediatric patients and lack systematic evaluation, particularly in the case of neonates. Third, although the novel biomarkers express rapidly after surgery, the discrepancies in sensitivity and specificity in different clinical settings are huge. Further work aiming to develop a joint application of traditional and novel biomarkers is needed in order to improve diagnostic accuracy.

\section{Renal near-infrared spectroscopy predicting neonatal CS-AKI}

Near-infrared spectroscopy (NIRS), a non-invasive, continuous and real-time monitor device, is used to detect regional oxygen saturation $\left(\mathrm{rSO}_{\mathrm{q}}\right)$, namely the oxygen content within the local tissue. This new technology is based on the different absorptions of near-infrared wavelengths by oxygenated and deoxygenated hemoglobin, known as the Beer-Lambert principle. The sensor could be placed on the forehead, the surface of the abdomen, or the left or right side of the spine at the T10-L2 level to detect the cerebral, abdominal and kidney $\mathrm{rSO}_{2}$, respectively. The neonatal cerebral $\mathrm{rSO}_{2}$ was recorded by Jobsis for the first time in $1977 .^{43}$ In 1991, NIRS was used as a non-invasive tool for evaluating the effect of hypothermic $\mathrm{CPB}$ and total circulatory arrest on pediatric cerebral metabolism. ${ }^{44}$ Since then, tremendous research has been implemented to assess the influence of ischemic insult on the neurological, renal and other organic functions by NIRS in neonates.

A study including 40 neonates and young infants indicates that patients with renal $\mathrm{rSO}_{2}<50 \%$ more than 2 hours within the first 24 hours after surgery are more susceptible to AKI. In addition, patients with permanently low renal $\mathrm{rSO}_{2}$ need longer mechanical ventilation and inotropic support. ${ }^{2445}$ Ruf et at ${ }^{46}$ continuously monitored the renal $\mathrm{rSO}_{2}$ intraoperatively and 24-48 hours postoperatively and found that intraoperative persistently low renal oximetry $(<65 \%)$ or significant decrease of oximetry $(>25 \%)$ was related to the occurrence of AKI and poor outcomes and that the diagnostic value of NIRS might surpass NGAL and cystatin C. These findings indicate that NIRS can be another promising noninvasive bedside monitor for the development of CS-AKI in neonates. Despite the inspiring results, NIRS still has several imperative shortcomings. First, the normal and pathological baseline for renal $\mathrm{rSO}_{2}$ is still lacking, and the variance between individuals is significant. Second, the value of renal $\mathrm{rSO}_{2}$ is easily influenced by the position, exogenous light, and cyanotic and non-cyanotic congenital heart diseases. Therefore, exploring a sensitive and specific combined diagnostic model consisting of NIRS and other chemical markers is inevitable in future work.

\section{CONCLUSION}

Neonatal patients are vulnerable to CS-AKI. Identifying the patients at high risk for CS-AKI facilitates timely intervention and improves outcome. UNGAL, serum cystatin C, uL-FABP, uKIM-1 and uIL-18 are the potential 
biomarkers for early prediction of CS-AKI in neonates. Continuous monitoring of renal $\mathrm{rSO}_{2}$ by NIRS could be a cost-effective complement in the early diagnosis of neonatal AKI. Further work should focus on exploring a sensitive and specific combined diagnostic model that includes novel biomarkers and non-invasive tools.

Acknowledgements We sincerely appreciate the Key Laboratory for Diagnosis and Therapy of Neonatal Diseases, the Children's Hospital of Zhejiang University School of Medicine for serving as the scientific advisers.

Contributors SSS collected the data and drafted the manuscript. FJJ analyzed the data and assisted in revising the manuscript. SQ designed the study and supervised the drafting of the manuscript. All authors had read and approved the final manuscript.

Funding The authors have not declared a specific grant for this research from any funding agency in the public, commercial or not-for-profit sectors.

Competing interests None declared.

Patient consent for publication Not required.

Ethics approval Not required for this review paper.

Provenance and peer review Not commissioned; externally peer reviewed.

Data availability statement Data sharing not applicable as no data sets generated and/or analyzed for this study. No data, models or codes were generated in this review paper.

Open access This is an open access article distributed in accordance with the Creative Commons Attribution Non Commercial (CC BY-NC 4.0) license, which permits others to distribute, remix, adapt, build upon this work non-commercially, and license their derivative works on different terms, provided the original work is properly cited, appropriate credit is given, any changes made indicated, and the use is non-commercial. See: http://creativecommons.org/licenses/by-nc/4.0/.

\section{REFERENCES}

1 Uchino S, Kellum JA, Bellomo R, et al. Acute renal failure in critically ill patients: a multinational, multicenter study. JAMA 2005;294:814-8

2 Bellomo R, Kellum JA, Ronco C. Acute kidney injury. Lancet 2012:380:756-66.

3 Li S, Krawczeski CD, Zappitelli M, et al. Incidence, risk factors, and outcomes of acute kidney injury after pediatric cardiac surgery: a prospective multicenter study*. Crit Care Med 2011;39:1493-9.

4 Morgan CJ, Zappitelli M, Robertson CMT, et al. Risk factors for and outcomes of acute kidney injury in neonates undergoing complex cardiac surgery. J Pediatr 2013;162:120-7.

5 Blinder JJ, Goldstein SL, Lee VV, et al. Congenital heart surgery in infants: effects of acute kidney injury on outcomes. J Thorac Cardiovasc Surg 2012;143:368-74.

6 Piggott KD, Soni M, Decampli WM, et al. Acute kidney injury and fluid overload in neonates following surgery for congenital heart disease. World J Pediatr Congenit Heart Surg 2015;6:401-6.

7 Bellomo R, Ronco C, Kellum JA, et al. Acute Dialysis Quality Initiative workgroup. Acute renal failure - definition, outcome measures, animal models, fluid therapy and information technology needs: the Second International Consensus Conference of the Acute Dialysis Quality Initiative (ADQI) Group. Crit Care 2004;8:R204-12.

8 Jetton JG, Guillet R, Askenazi DJ, et al. Assessment of worldwide acute kidney injury epidemiology in neonates: design of a retrospective cohort study. Front Pediatr 2016;19:68.

9 Mehta RL, Kellum JA, Shah SV, et al. Acute kidney injury network: report of an initiative to improve outcomes in acute kidney injury. Crit Care 2007;11:R31.

10 Ricci Z, Ronco C. Neonatal rifle. Nephrol Dial Transpl 2013;28:2211-4.

11 Lex DJ, Tóth R, Cserép Z, et al. A comparison of the systems for the identification of postoperative acute kidney injury in pediatric cardiac patients. Ann Thorac Surg 2014;97:202-10.

12 Sutherland L, Hittesdorf E, Yoh N, et al. Acute kidney injury after cardiac surgery: a comparison of different definitions. Nephrology 2020;25:212-8.

13 Jetton JG, Askenazi DJ. Update on acute kidney injury in the neonate. Curr Opin Pediatr 2012;24:191-6.
14 Hinchliffe SA, Sargent PH, Howard CV, et al. Human intrauterine renal growth expressed in absolute number of glomeruli assessed by the disector method and Cavalieri principle. Lab Invest 1991:64:777-84.

15 Abitbol CL, Seeherunvong W, Galarza MG, et al. Neonatal kidney size and function in preterm infants: what is a true estimate of glomerular filtration rate? J Pediatr 2014;164:1026-31.

16 Krawczeski CD, Woo JG, Wang Y, et al. Neutrophil gelatinaseassociated lipocalin concentrations predict development of acute kidney injury in neonates and children after cardiopulmonary bypass. J Pediatr 2011;158:1009-15.

17 Cantinotti M, Storti S, Lorenzoni V, et al. The combined use of neutrophil gelatinase-associated lipocalin and brain natriuretic peptide improves risk stratification in pediatric cardiac surgery. Clin Chem Lab Med 2012;50:2009-17.

18 Ricci Z, Netto R, Garisto C, et al. Whole blood assessment of neutrophil gelatinase-associated lipocalin versus pediatricRIFLE for acute kidney injury diagnosis and prognosis after pediatric cardiac surgery. Pediatr Crit Care Med 2012;13:667-70.

19 Mamikonian LS, Mamo LB, Smith PB, et al. Cardiopulmonary bypass is associated with hemolysis and acute kidney injury in neonates, infants, and Children*. Pediatr Crit Care Med 2014;15:e111-9.

20 Alcaraz AJ, Gil-Ruiz MA, Castillo A, et al. Postoperative neutrophil Gelatinase-Associated lipocalin predicts acute kidney injury after pediatric cardiac Surgery*. Pediatr Crit Care Med 2014:15:121-30.

21 Bojan M, Basto Duarte MC, Ermak N, et al. Structural equation modelling exploration of the key pathophysiological processes involved in cardiac surgery-related acute kidney injury in infants. Crit Care 2016;20:171

22 Herbert C, Patel M, Nugent A, et al. Serum cystatin C as an early marker of neutrophil gelatinase-associated Lipocalin-positive acute kidney injury resulting from cardiopulmonary bypass in infants with congenital heart disease. Congenit Heart Dis 2015;10:E180-8.

23 Peco-Antić A, Ivanišević I, Vulićević I, et al. Biomarkers of acute kidney injury in pediatric cardiac surgery. Clin Biochem 2013;46:1244-51.

24 Hazle MA, Gajarski RJ, Aiyagari R, et al. Urinary biomarkers and renal near-infrared spectroscopy predict intensive care unit outcomes after cardiac surgery in infants younger than 6 months of age. J Thorac Cardiovasc Surg 2013;146:861-7.

25 Schroeder LW, Buckley JR, Stroud RE, et al. Plasma neutrophil gelatinase-associated lipocalin is associated with acute kidney injury and clinical outcomes in neonates undergoing cardiopulmonary bypass. Pediatric Critical Care Medicine 2019;20:957-62.

26 Reiter K, Balling G, Bonelli V, et al. Neutrophil gelatinase-associated lipocalin reflects inflammation and is not a reliable renal biomarker in neonates and infants after cardiopulmonary bypass: a prospective case-control study. Cardiol Young 2018;28:243-51.

27 Gist KM, Cooper DS, Wrona J, et al. Acute kidney injury biomarkers predict an increase in serum milrinone concentration earlier than serum Creatinine-Defined acute kidney injury in infants after cardiac surgery. Ther Drug Monit 2018;40:186-94.

28 Elmas AT, Tabel Y, Elmas ON. Serum cystatin C predicts acute kidney injury in preterm neonates with respiratory distress syndrome. Pediatr Nephrol 2013;28:477-84.

29 Li Y, Li X, Zhou X, et al. Impact of sepsis on the urinary level of interleukin-18 and cystatin C in critically ill neonates. Pediatr Nephrol 2013;28:135-44.

30 Yang Y, Wu Y, Pan JJ, et al. Change of cystatin C values in preterm infants with asphyxia-From two centers of China. J Clin Lab Anal 2017:31:e22070.

31 Hassinger AB, Backer CL, Lane JC, et al. Predictive power of serum cystatin $\mathrm{C}$ to detect acute kidney injury and pediatric-modified rifle class in children undergoing cardiac surgery. Pediatr Crit Care Med 2012;13:435-40.

32 Seitz S, Rauh M, Gloeckler M, et al. Cystatin C and neutrophil gelatinase-associated lipocalin: biomarkers for acute kidney injury after congenital heart surgery. Swiss Med Wkly 2013;143:w13744.

33 Morgan CJ, Gill PJ, Lam S, et al. Peri-Operative interventions, but not inflammatory mediators, increase risk of acute kidney injury after cardiac surgery: a prospective cohort study. Intensive Care Med 2013;39:934-41.

34 Liu KD, Altmann C, Smits G, et al. Serum interleukin-6 and interleukin-8 are early biomarkers of acute kidney injury and predict prolonged mechanical ventilation in children undergoing cardiac surgery: a case-control study. Crit Care 2009;13:R104.

35 Zheng J, Xiao Y, Yao Y, et al. Comparison of urinary biomarkers for early detection of acute kidney injury after cardiopulmonary bypass surgery in infants and young children. Pediatr Cardiol 2013;34:880-6. 
36 Kashani K, Al-Khafaji A, Ardiles T, et al. Discovery and validation of cell cycle arrest biomarkers in human acute kidney injury. Crit Care 2013;17:R25.

37 Meersch M, Schmidt C, Van Aken H, et al. Validation of cell-cycle arrest biomarkers for acute kidney injury after pediatric cardiac surgery. PLoS One 2014;9:e110865.

38 Burra V, Nagaraja PS, Singh NG, et al. Early prediction of acute kidney injury using serum phosphorus as a biomarker in pediatric cardiac surgical patients. Ann Card Anaesth 2018;21:455-9.

39 Volovelsky O, Terrell TC, Swain H, et al. Pre-Operative level of FGF23 predicts severe acute kidney injury after heart surgery in children. Pediatr Nephrol 2018;33:2363-70.

40 Tew S, Fontes ML, Greene NH, et al. Natural history of nonimmunemediated thrombocytopenia and acute kidney injury in pediatric open-heart surgery. Paediatr Anaesth 2017;27:305-13.

41 Zappitelli M, Coca SG, Garg AX, et al. The association of albumin/ creatinine ratio with postoperative $\mathrm{AKI}$ in children undergoing cardiac surgery. CJASN 2012;7:1761-9.

42 Shi SS, Yue XJ, Zhao DY, et al. Plasma gelsolin level predicts acute kidney injury after cardiopulmonary bypass in infants and young children. World J Pediatr 2018;14:143-50.

43 Jobsis F. Noninvasive, infrared monitoring of cerebral and myocardial oxygen sufficiency and circulatory parameters. Science 1977;198:1264-7.

45 Greeley WJ, Bracey VA, Ungerleider RM, et al. Recovery of cerebral metabolism and mitochondrial oxidation state is delayed after hypothermic circulatory arrest. Circulation 1991;84:III400-6.

45 Owens GE, King K, Gurney JG, et al. Low renal oximetry correlates with acute kidney injury after infant cardiac surgery. Pediatr Cardiol 2011;32:183-8.

46 Ruf B, Bonelli V, Balling G, et al. Intraoperative renal near-infrared spectroscopy indicates developing acute kidney injury in infants undergoing cardiac surgery with cardiopulmonary bypass: a casecontrol study. Crit Care 2015;19:27.

47 DeSena HC, Nelson DP, Cooper DS. Cardiac intensive care for the neonate and child after cardiac surgery. Curr Opin Cardiol 2015;30:81-8.

48 Salmasi V, Maheshwari K, Yang D, et al. Relationship between intraoperative hypotension, defined by either reduction from baseline or absolute thresholds, and acute kidney and myocardial injury after noncardiac surgery. Anesthesiology 2017;126:47-65.
49 Gaies MG, Gurney JG, Yen AH, et al. Vasoactive-inotropic score as a predictor of morbidity and mortality in infants after cardiopulmonary bypass*. Pediatr Crit Care Med 2010;11:234-8.

50 Park SK, Hur M, Kim E, et al. Risk factors for acute kidney injury after congenital cardiac surgery in infants and children: a retrospective observational study. PLoS One 2016;11:e0166328.

51 Billings FT, Ball SK, Roberts LJ, et al. Postoperative acute kidney injury is associated with hemoglobinemia and an enhanced oxidative stress response. Free Radic Biol Med 2011;50:1480-7.

52 Billings FT, Yu C, Byrne JG, et al. Heme oxygenase-1 and acute kidney injury following cardiac surgery. Cardiorenal Med 2014;4:12-21.

53 Meersch M, Zarbock A. Prevention of cardiac surgery-associated acute kidney injury. Curr Opin Anaesthesiol 2017;30:76-83.

54 Jönsson S, Agic MB, Narfström F, et al. Renal neurohormona regulation in heart failure decompensation. Am J Physiol Regul Integr Comp Physiol 2014;307:R493-7.

55 Arcinue R, Kantak A, Elkhwad M. Acute kidney injury in ELBW infants. J Neonatal Perinatal Med 2015;8:349-57.

56 Selewski DT, Charlton JR, Jetton JG, et al. Neonatal acute kidney injury. Pediatrics 2015;136:e463-73.

57 Jang WS, Kim WH, Choi K, et al. Incidence, risk factors and clinical outcomes for acute kidney injury after aortic arch repair in paediatric patients. Eur J Cardiothorac Surg 2014;45:e208-14.

58 Basu RK, Chawla LS, Wheeler DS, et al. Renal angina: an emerging paradigm to identify children at risk for acute kidney injury. Pediatr Nephrol 2012;27:1067-78.

59 Miklaszewska M, Korohoda P, Sobczak A, et al. Acute kidney injury in a single pediatric intensive care unit in Poland: a retrospective study. Kidney Blood Press Res 2014;39:28-39.

60 AlAbbas A, Campbell A, Skippen P, et al. Epidemiology of cardiac surgery-associated acute kidney injury in neonates: a retrospective study. Pediatr Nephrol 2013;28:1127-34.

61 Carlo WF, Clark ST, Borasino S, et al. Impact of contrast exposure from computed tomography angiography on acute kidney injury after neonatal cardiopulmonary bypass surgery. Congenit Heart Dis 2017;12:540-5.

62 SooHoo M, Griffin B, Jovanovich A, et al. Acute kidney injury is associated with subsequent infection in neonates after the Norwood procedure: a retrospective chart review. Pediatr Nephrol 2018;33:1235-42. 